\title{
DIRECT POWER CONTROL OF A DOUBLY FED INDUCTION GENERATOR BY USING A NEURO-FUZZY CONTROLLER
}

\author{
Rogério Vani Jacomini and Edson Bim \\ State University of Campinas - UNICAMP \\ School of Electrical and Computer Engineering - P.O. Box 6101 - 13083-852 Campinas Brazil \\ jacomini@dsce.fee.unicamp.br and bim@dsce.fee.unicamp.br
}

\begin{abstract}
In this article, a direct power control strategy for a doubly fed induction generation is presented. The control variables $-d$-axis and $q$-axis rotor voltages - are determined through a control system that consists of a neuro-fuzzy inference system and a Takagi-Sugeno fuzzy logic controller of first order. The input variables of the control system are the rotor speed, active and reactive power references, and their respective errors. Constant converter switching frequency is achieved, what eases the design of ac harmonic filter and reduced the power loss in the power converter. Another features are the rotor current-sensorless operation, lower cost implementation and the gain of reliability. To validate the strategy, simulation and experimental results are presented for abrupt and linear variations of active and reactive power.
\end{abstract}

Keywords - Constant Converter Switching Frequency, Space Vector Modulation, Doubly Fed Induction Generation, Direct Power Control, Neuro-Fuzzy Inference System, Takagi-Sugeno Fuzzy Logic Controller.

\section{LIST OF SYMBOLS}

$\begin{array}{ll}R_{s}, R_{r} & \text { stator, rotor resistances. } \\ L_{s}, L_{r}, L_{m} & \text { stator self, rotor self, mutual inductances. } \\ \sigma & \text { total leakage factor. } \\ \omega_{1}, \omega_{2}, \omega_{r} & \text { synchronous, slip, rotor angular frequency. } \\ \theta_{1}, \theta_{2}, \theta_{r} & \text { stator flux,slip, rotor angles. } \\ P, Q & \text { active and reactive power. } \\ \bar{V}, \bar{I}, \bar{\psi} & \text { voltage, current, flux space vectors. } \\ v, i, \psi & \text { voltage, current, flux components. } \\ \bar{X}=x+j y & \text { space vector expressed in the general } \\ & \text { reference frame } \\ s, r & \text { stator and rotor, respectively. } \\ \alpha, \beta & \text { direct- and quadrature-axis expressed in } \\ & \text { the stationary reference frame. } \\ d, q & \text { direct- and quadrature-axis expressed in } \\ & \text { the synchronous reference frame. } \\ m, n & \text { direct- and quadrature-axis expressed in } \\ & \text { the rotor reference frame. }\end{array}$

\section{INTRODUCTION}

It is seen in the literature a great interest in the doubly fed induction machine (DFIM) as an attractive alternative to cage rotor induction machines and synchronous machines in high power applications [1]. The interest excels in applications such as: generator for renewable energy $[2,3]$ and motor for ventilation systems and pumps [4]. For such applications,

Artigo submetido em 11/08/2011. Revisado em 09/11/2011. Aceito para publicao em 23/11/2011 por recomendao do editor João Onofre P. Pinto. the stator windings are directly connected to the constant frequency three phase grid and the rotor windings are supplied by a bidirectional power converter that is designed to handle about $\pm 25 \%$ of the machines rating [2], what becomes attractive the use of DFIM in large power systems. A strategy to make better use of converters and improve the ability to control the total reactive power grid is proposed by [5].

Among all methods of active and reactive power control for doubly fed induction machine, nowadays, the direct control techniques have become a well-known strategy for high dynamic performances. Based on the conventional direct torque control (DTC) [6], a conventional direct power control (DPC) for the control of active and reactive power of the DFIG was developed by [7], by using hysteresis controllers associated with a switching table. It has the feature to generate directly the required rotor control voltage from the errors of controlled power without the necessity of PI controllers, which are the bases of the articles [8,9]. PI controles are also applied to DFIG under grid voltages dips conditions [10]. However, the conventional DPC strategy requires a high sampling frequency for digital implementations. Added to this the following disadvantages: variable switching frequency, high power ripples and current distortions [7, 11].

A solution to the problem caused by the hysteresis controllers is the DTC with space vector modulation (SVM) schemes [12-14]. The DPC strategies with SVM are applied to DFIG are presented in $[15,16]$. In these strategies, the controller calculates the required rotor voltage components which, in turn, are used to generate the switching signal for the SVM convertor. These rotor voltage components can be calculated from stator flux, the active and reactive power as well as from their errors [15]. In [16], PI controllers are used to determine rotor voltage components from power errors.

Intelligent controls using fuzzy logic, neural networks, neuro-fuzzy system and generic algorithms have been recently recognized as important tools to enhance the performance of the power electronic systems [17, 18]. Particularly, among the advantages of neuro-fuzzy system are the training easy, generalization and simple architecture [17], besides being used in a several different applications $[4,19,20]$. The rules base and membership functions of a neuro-fuzzy system are easily obtained in an automated process by an ANFIS, from the input-output data set, where the parameters associated with the output and input membership functions are adjusted by the combination of back propagation learning algorithm with a least squares type algorithm $[19,20]$. Thus, the neurofuzzy based controller is an effective way of controlling torque or power. In Grabowski [21] proposed a direct torque control technique of induction motors based on adaptive neuro-fuzzy inference system (ANFIS) for the voltage space 
vector generation. The technique was characterized by simple self-tuning procedure and good steady-state and dynamic performance, but it was applied to squirrel cage induction motor.

In this paper a neuro-fuzzy controller design for the direct control of active and reactive power of a DFIG is proposed, being adopted SVM for power converter. The first stage of this project is the acquisition of data sets for training, which are used by ANFIS that has the function of building the neuro-fuzzy system. For this, it was initially performed simulation of a stator-flux-oriented control of DFIG employing PI controllers in cascade for obtaining of 135 training data for 27 operation points which are obtained from different tunings of PI controllers. Once built the neuro-fuzzy system, a Takagi-Sugeno fuzzy logic controller (T-S FLC) is designed in order to increase the response of the stator active and reactive power control and minimize their errors. Simulation and experimental results of the proposed strategy are presented.

\section{FUNDAMENT OF DIRECT POWER CONTROL TO DOUBLY FED INDUCTION GENERATOR}

\section{A. DFIG Model}

The stator flux oriented mathematical model $\left(\psi_{s q}=0\right)$ of the Doubly Fed Induction Generator (DFIG) is written in the synchronous reference frame and with negligible stator resistance $R_{s}$ is given by the following set of equations [22]:

- Stator and rotor flux space vectors

$$
\begin{aligned}
& \bar{\psi}_{s d q}=L_{s} \bar{I}_{s d q}+L_{m} \bar{I}_{r d q} \\
& \bar{\psi}_{r d q}=L_{r} \bar{I}_{r d q}+L_{m} \bar{I}_{s d q}
\end{aligned}
$$

- Stator and rotor voltage space vectors

$$
\begin{gathered}
\bar{V}_{s d q}=\frac{d \bar{\psi}_{s d q}}{d t}+j \omega_{1} \bar{\psi}_{s d q} \\
\bar{V}_{r d q}=R_{r} \bar{I}_{r d q}+\frac{d \bar{\psi}_{r d q}}{d t}+j \omega_{2} \bar{\psi}_{r d q}
\end{gathered}
$$

- Stator active and reactive power

$$
\begin{aligned}
P_{s} & =\frac{3}{2} \Re e\left(\bar{V}_{s d q} \cdot \bar{I}_{s d q}\right) \\
Q_{s} & =\frac{3}{2} \Im m\left(\bar{V}_{s d q} \cdot \bar{I}_{s d q}\right)
\end{aligned}
$$

According to equations (1) and (2), the stator and rotor currents are given as

$$
\begin{gathered}
\bar{I}_{s d q}=\frac{\bar{\psi}_{s d q}}{\sigma L_{s}}-\frac{L_{m} \bar{\psi}_{r d q}}{\sigma L_{s} L_{r}} \\
\bar{I}_{r d q}=\frac{\bar{\psi}_{r d q}}{\sigma L_{r}}-\frac{L_{m} \bar{\psi}_{s d q}}{\sigma L_{s} L_{r}}
\end{gathered}
$$

in which $\sigma=\left(L_{s} L_{r}-L_{m}^{2}\right) / L_{s} L_{r}$ is the leakage factor.

Combining the equations (3), (7), (5) and (6), one obtain after some algebraic manipulations the following power equations:

$$
P_{s}=-k_{\sigma} \omega_{1} \psi_{s d} \psi_{r q}
$$

$$
Q_{s}=k_{\sigma} \omega_{1} \psi_{s d}\left(\frac{L_{r}}{L_{m}} \psi_{s d}-\psi_{r d}\right)
$$

where $k_{\sigma}$ is a constant given by $k_{\sigma}=1.5 L_{m} / \sigma L_{s} L_{r}$.

As the stator flux $\psi_{s d}$ and synchronous frequency $\omega_{1}$ are maintained constants (assumption of infinite bus), the stator active and reactive power can be controlled by means of $\psi_{r q}$ and $\psi_{r d}$, respectively.

From the equations (9) and (10), the components of the rotor flux are given by

$$
\begin{gathered}
\psi_{r q}=-\frac{1}{k_{\sigma} \omega_{1} \psi_{s d}} P_{s} \\
\psi_{r d}=\frac{L_{r}}{L_{m}} \psi_{s d}-\frac{1}{k_{\sigma} \omega_{1} \psi_{s d}} Q_{s}
\end{gathered}
$$

In accordance with the equations (11) and (12), if the sampling period $T_{s}$ is small [15], the rotor flux changes in the $\mathrm{d}-\mathrm{q}$ axis depend on the active and reactive power changes:

$$
\begin{aligned}
& \Delta \psi_{r q}=-\frac{1}{k_{\sigma} \omega_{1} \psi_{s d}} \Delta P s \\
& \Delta \psi_{r d}=-\frac{1}{k_{\sigma} \omega_{1} \psi_{s d}} \Delta Q_{s} .
\end{aligned}
$$

where $\Delta P_{s}$ and $\Delta Q_{s}$ are the active and reactive power errors, respectively.

\section{B. Direct Power Control}

In the direct power control the controlled variables are the stator active and reactive power, and the control variables are the direct and quadrature axis rotor voltage.

For a constant period $T_{s}$ the expressions of rotor voltage components are obtained from the substitution of the equation (8) into (4), resulting:

$$
\begin{gathered}
v_{r d}=\frac{\Delta \psi_{r d}}{T_{s}}+\frac{R_{r} \psi_{r d}}{\sigma L_{r}}-\frac{R_{r} L_{m} \psi_{s d}}{\sigma L_{s} L_{r}}-\omega_{2} \psi_{r q} \\
v_{r q}=\frac{\Delta \psi_{r q}}{T_{s}}+\frac{R_{r} \psi_{r q}}{\sigma L_{r}}+\omega_{2} \psi_{r d}
\end{gathered}
$$

Substituting equations (11)-(14) in the equations (15) and (16), the reference values of the $v_{r d}$ and $v_{r q}$ in function of $P_{s}^{*}$, $Q_{s}^{*}, \Delta P_{s}$ e $\Delta Q_{s}$ are calculated in discrete form as

$$
\begin{array}{r}
v_{r d}^{*}(k)=-c_{1} \frac{\Delta Q_{s}(k)}{T_{s}}+\frac{R_{r}}{L_{m}} \psi_{s d}-c_{2} Q_{s}^{*}(k+1)+ \\
+c_{1} \omega_{2} P_{s}^{*}(k+1) \\
\begin{array}{r}
v_{r q}^{*}(k)=-c_{1} \frac{\Delta P_{s}(k)}{T_{s}}+\frac{L_{r}}{L_{m}} \omega_{2} \psi_{s d}-c_{1} \omega_{2} Q_{s}^{*}(k+1)- \\
-c_{2} P_{s}^{*}(k+1)
\end{array}
\end{array}
$$

where $P_{s}^{*}(k+1)$ and $Q_{s}^{*}(k+1)$ are the future references, $P_{s}(k)$ and $Q_{s}(k)$ are the measured values at sampling time $k$, $\Delta P_{s}(k)=P_{s}^{*}(k+1)-P_{s}(k), \Delta Q_{s}(k)=Q_{s}^{*}(k+1)-Q_{s}(k)$, $c_{1}=1 /\left(k_{\sigma} \omega_{1} \psi_{s d}\right)$ and $c_{2}=R_{r} /\left(\sigma k_{\sigma} L_{r} \omega_{1} \psi_{s d}\right)$. 


\section{PROPOSED DIRECT POWER CONTROL}

The control system consists of NFIS combined with T-S FLC, i.e., for the generation of each component $v_{r d}^{*}$ and $v_{r q}^{*}$ there is a NFIS combined with a T-S FLC, as is illustrated in Figure 1. In a given period of $T_{s}$ the first generates the required rotor voltages $v_{r d}(k)$ and $v_{r q}(k)$ from rotor electrical speed $\omega_{r}(k)$ and future references of the active and reactive power; the second generates the increments $\Delta v_{r d}(k)$ and $\Delta v_{r q}(k)$ and it provides a quick response of the powers and reduces their errors.

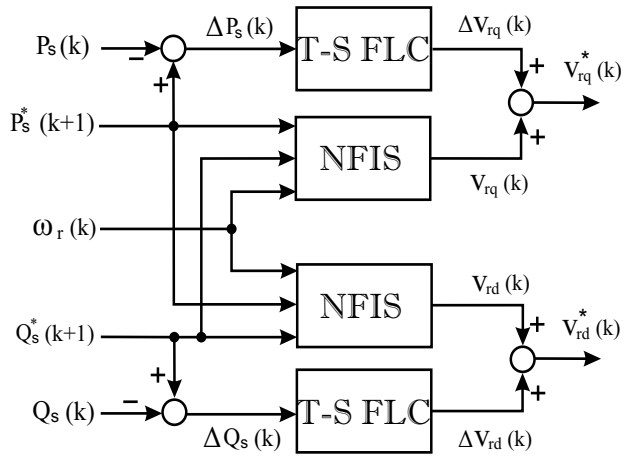

Fig. 1. Block diagram of the control system.

\section{A. Adaptative Neural-Fuzzy Inference System and Training}

The NFS and the rule base were constructed by an off-line adaptive neural-fuzzy inference system (ANFIS) [19]. The structure of the NFIS is based on Takagi-Sugeno [23] and consists of 27 rules for each one of the components $v_{r d}^{*}(k)$ and $v_{r q}^{*}(k)$, where each rule's consequent is specified by a fuzzy singleton.

The data set for training the ANFIS was obtained from PI controllers in cascade, were sampled 135 training data for 27 operation point (OP), where different tunings were required for different operation points. The training data and the DFIG parameters are shown in Appendix.

According to the property of ANFIS, it is only suitable to the multiple input and single output system. Therefore, as the proposed system requires three inputs and two outputs, then are used two ANFIS: one to provide $v_{r d}^{*}$ (ANFIS 1) and another to provide $v_{r q}^{*}$ (ANFIS 2). The structure of the implemented ANFIS is presented in Figure 2 which is formed by a zero-order Sugeno fuzzy model [23], with rules 27 .

- layer 1: All nodes in this layer are adaptive, with the function defined by

$$
\begin{aligned}
O_{1, i} & =\mu^{A_{i}}\left(T_{e m}^{*}\right), i=1,3 \\
O_{1,(i+2)} & =\mu^{B_{i}}\left(Q_{s}^{*}\right), i=1,3 \\
O_{1,(i+4)} & =\mu^{C_{i}}\left(\omega_{r}\right), i=1,3
\end{aligned}
$$

where $P_{s}^{*}, Q_{s}^{*}$ and $\omega_{r}$ are the inputs in the nodes $O_{1}$ and $A_{i}$, $B_{i}$ and $C_{i}$ are the linguistic variables associated with these nodes. At the implementation the linguistic variables were denoted triangular function.

- layer 2: The outputs of each node in this layer are the firing strength $w_{j}$, that are determined by T-norm operators,
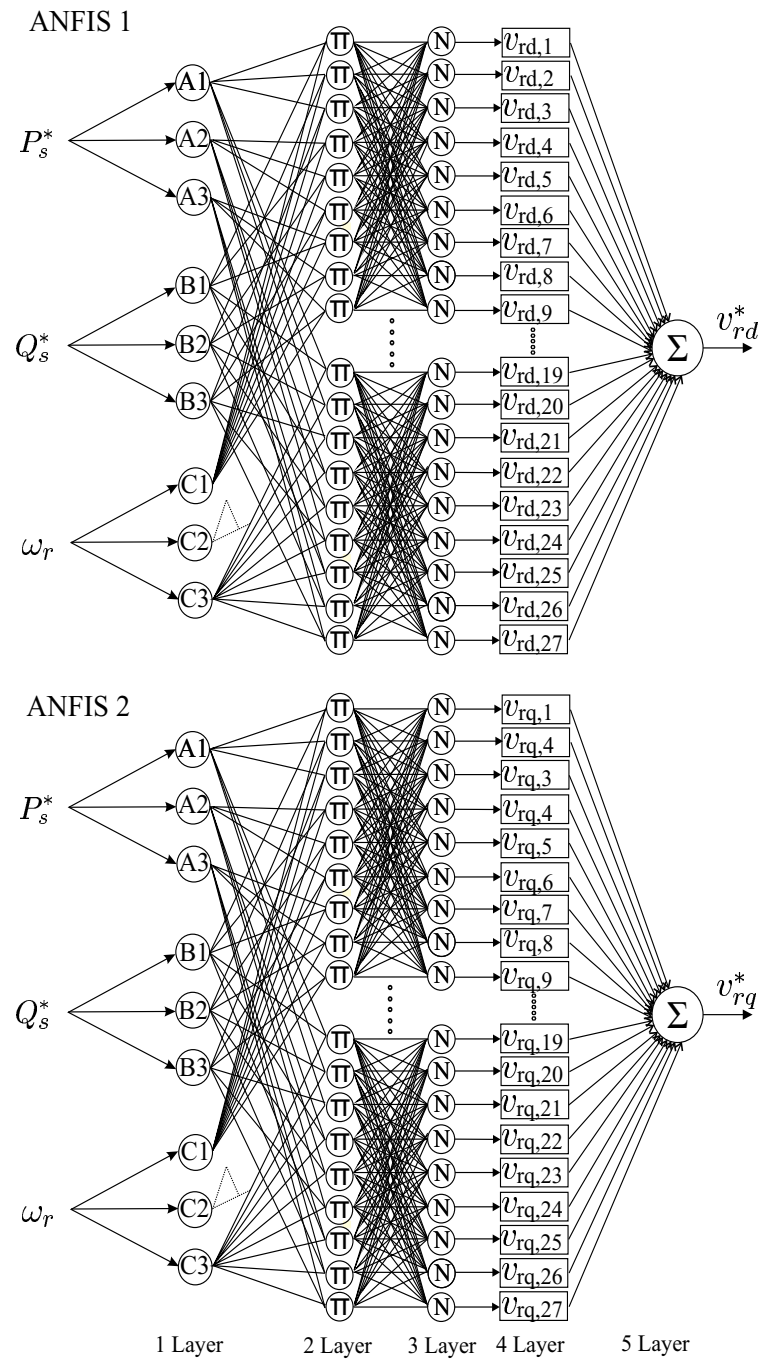

Fig. 2. Implemented ANFIS architecture.

defined by algebraic product (П Neuron).

$$
O_{2, j}=w_{j}=\left[\mu^{A}\left(P_{s}^{*}\right) \times \mu^{B}\left(Q_{s}^{*}\right)\right] \times \mu^{C}\left(\omega_{r}\right),
$$

for $\mathrm{j}=1,2, \ldots, 27$.

- layer 3: The firing strength of each rule are normalized via $\mathrm{N}$ neuron, resulting in

$$
O_{3, j}=\bar{w}_{j}=\frac{w_{j}}{w_{1}+w_{2}+w_{3}+\ldots+w_{27}},
$$

for $\mathrm{j}=1,2, \ldots, 27$.

-layer 4: All nodes in this layer are adaptive. The outputs of the nodes are calculated by the product of the normalized firing strengths and value of membership function for a "zeroorder Sugeno fuzzy model”,

$$
O_{4, j}=\bar{w}_{j}\left(r_{j}\right)
$$

for $\mathrm{j}=1,2, \ldots, 27$. Where $r_{j}$ is the parameter of the consequents of $v_{r d, j}$ and $v_{r q, j}$.

- layer 5: In this last layer, the output $O_{5}$ of the neuro-fuzzy 
system is calculated by

$$
O_{5}=\sum_{j=1}^{27} \bar{w}(j) O_{4, j}
$$

Where $O_{5}$ can be $v_{r d}^{*}$ or $v_{r q}^{*}$

After training of the ANFIS, the membership functions of input that allow obtain the voltages $v_{r d}$ and $v_{r q}$ are established by triangular functions, and the consequent of each rule is a singleton function, as shown in Figures 3 and 4.
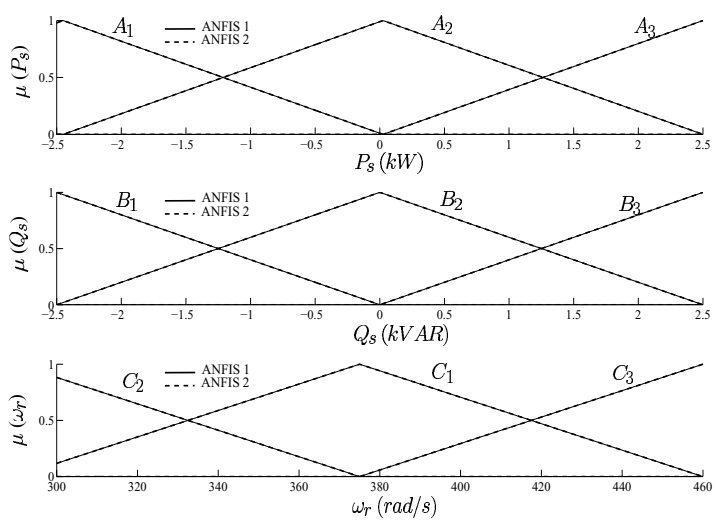

Fig. 3. Membership function for three input.
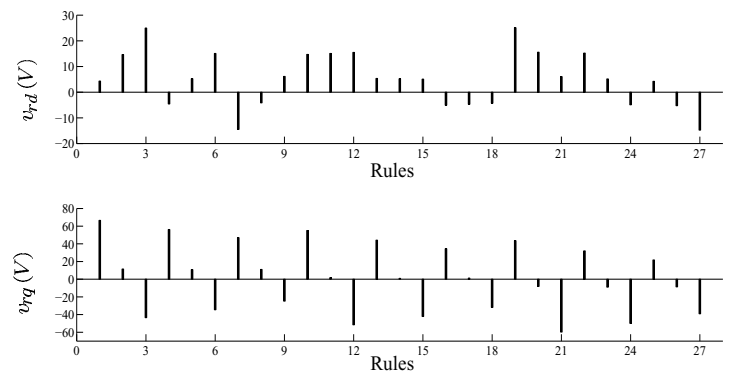

Fig. 4. Each rule's output.

The membership functions generated by ANFIS 1 and ANFIS 2 after training are equal, as seen in Figure 3. Therefore we can simplify the system shown in Figure 2 for the system shown in Figure 5, given the fact that until third law is equal.

The direct relationship between input $\left(P_{s}^{*}, Q_{s}^{*}\right.$ and $\left.\omega_{r}\right)$ and output $\left(v_{r d}^{*}\right.$ and $\left.v_{r q}^{*}\right)$, generated by ANFIS, allowed to eliminate the current loop and consequently, the current sensors, but two additional loops are necessary: one that generates the increment $\Delta v_{r d}$ and another, the increment $\Delta v_{r q}$.

\section{B. Proposed T-S FLC}

The proposed TS-FLC determines the increments $\Delta v_{r q}$ and $\Delta v_{r d}$, from the error of active power $\Delta P_{s}$ and reactive power $\Delta Q_{s}$, respectively. Figure 6(a) shows the membership functions of input variables formed by three triangular

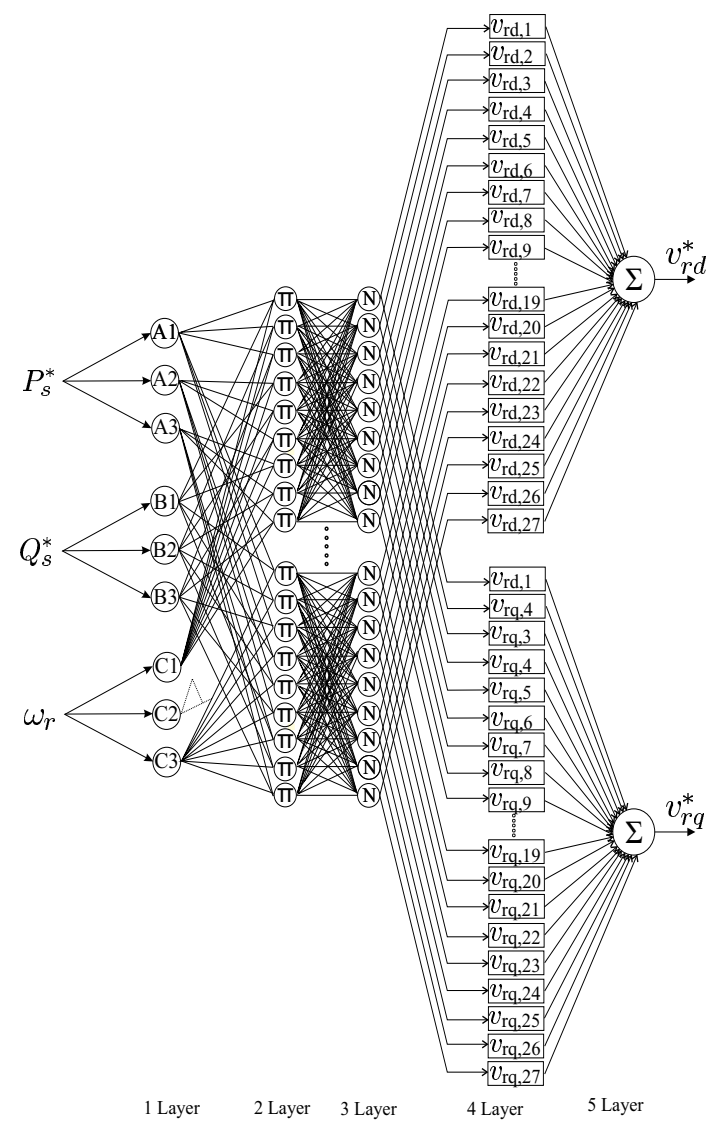

Fig. 5. Proposed NFIS architecture.

functions: negative $(N)$, positive $(P)$ and zero $(Z E)$. To activate the necessary rules for the proper performance of the controller, the gains $G_{p s}$ and $G_{q s}$ are introduced.

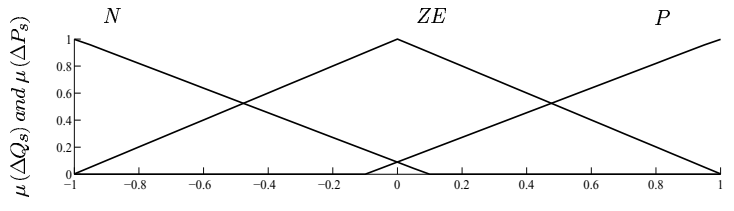

$\Delta Q_{s}$ and $\Delta P$

(a) Membership function for inputs

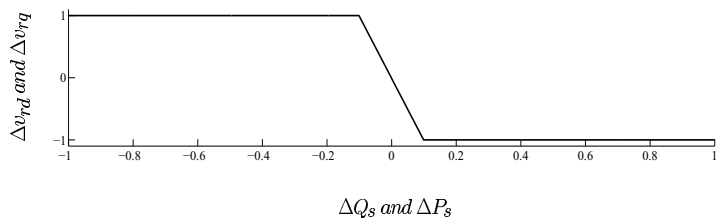

(b) Behavior of $\Delta v_{r d}$ and $\Delta v_{r q}$ in terms of $\Delta Q_{s}$ and $\Delta P_{s}$.

Fig. 6. Membership function for inputs $\Delta Q_{s}$ and $\Delta P_{s}$, and behavior of respective outputs $\Delta v_{r d}$ and $\Delta v_{r q}$ in function of $\Delta Q_{s}$ and $\Delta P_{s}$.

For each rule's consequent, the values of $\Delta v_{r d}$ and $\Delta v_{r q}$ are specified by a first-order T-S model. In Figure 6(b) it is illustrated the behavior of these increments in function of the variables $\Delta Q_{s}$ and $\Delta P_{s}$, respectively. The outputs of the TS- 
FLC ( $\Delta v_{r d}$ and $\left.\Delta v_{r q}\right)$ act to reduce the respective errors: if the error of the active power and reactive power is positive then their outputs will have a decrement: if the error is zero, the output variable will be zero.

The overall output of the T-S FLC implemented is the weighted average of the three individual outputs, given by

$$
\begin{aligned}
\Delta v_{d r}\left(\Delta Q_{s}\right) & =\frac{\mu_{N} \Delta v_{r d}^{(1)}+\mu_{Z E} \Delta v_{d r}^{(2)}+\mu_{P} \Delta v_{r d}^{(3)}}{\mu_{N}+\mu_{Z E}+\mu_{P}} \\
\Delta v_{r q}\left(\Delta P_{s}\right) & =\frac{\mu_{N} \Delta v_{r q}^{(1)}+\mu_{Z E} \Delta v_{r q}^{(2)}+\mu_{P} \Delta v_{r q}^{(3)}}{\mu_{N}+\mu_{Z E}+\mu_{P}}
\end{aligned}
$$

where

$$
\begin{gathered}
\Delta v_{r d}^{(1)}=11.22+12.25 \Delta Q_{s} \\
\Delta v_{r d}^{(2)}=10.28+0.0048 \Delta Q_{s} \\
\Delta v_{r d}^{(3)}=11.22-12.25 \Delta Q_{s} \\
\Delta v_{r q}^{(1)}=11.22+12.25 \Delta P_{s} \\
\Delta v_{r q}^{(2)}=10.28+0.0048 \Delta P_{s} \\
\Delta v_{r q}^{(3)}=11.22-12.25 \Delta P_{s}
\end{gathered}
$$

For the outputs are introduced the gains $G_{v r d}$ and $G_{v r q}$ to match the values generated by weighting with the actual values of output variables of the controller. In Figure 7 is shown the architecture of the T-S FLC implemented.

The rule sets R1, R2 and R3 which set the increments of $\Delta v_{r d}$ and $\Delta v_{r d}$ are as follows

$$
R 1: I F\left(\Delta Q_{s} \text { or } \Delta P_{s}\right) I S(N) T H E N
$$

$\left(\Delta v_{r d}^{(1)}=a_{0}^{(1)}+a_{1}^{(1)} \Delta Q_{s}\right.$ or $\left.\Delta v_{r q}^{(1)}=a_{0}^{(1)}+a_{1}^{(1)} \Delta P_{s}\right)$

$R 2: I F\left(\Delta Q_{s}\right.$ or $\left.\Delta P_{s}\right) I S(Z E) T H E N$

$\left(\Delta v_{r d}^{(2)}=a_{0}^{(2)}+a_{1}^{(2)} \Delta Q_{s}\right.$ or $\left.\Delta v_{r q}^{(2)}=a_{0}^{(2)}+a_{1}^{(2)} \Delta P_{s}\right)$

$$
R 3: I F\left(\Delta Q_{s} \text { or } \Delta P_{s}\right) I S(P) T H E N
$$

$$
\left(\Delta v_{r d}^{(3)}=a_{0}^{(3)}+a_{1}^{(3)} \Delta Q_{s} \text { or } \Delta v_{r q}^{(3)}=a_{0}^{(3)}+a_{1}^{(3)} \Delta P_{s}\right)
$$

\section{Description of the Implemented Control System}

The schematic diagram of the implemented control system is shown in Figure 8. The stator flux estimation and its angle $\theta_{1}$ are performed using the following equations:

$$
\begin{gathered}
\bar{\psi}_{s \alpha \beta}=\int\left(\bar{V}_{s \alpha \beta}-R_{s} \bar{I}_{s \alpha \beta}\right) d t, \\
\theta_{1}=\arctan \left(\frac{\psi_{s \beta}}{\psi_{s \alpha}}\right)
\end{gathered}
$$

The Neuro-Fuzzy Controller algorithm generates the reference components $v_{d r}^{*}$ and $v_{q r}^{*}$ and allow the active and reactive power to follow their respective reference values.

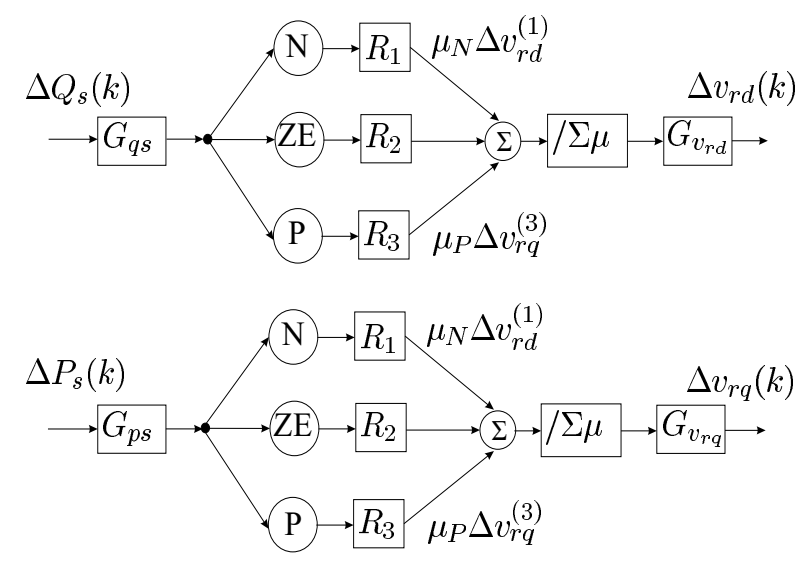

Fig. 7. Proposed T-S FLC architecture.

These components are expressed in the rotor reference frame by

$$
\bar{V}_{r m n}=v_{r m}+j v_{r n}=\bar{V}_{r d q} e^{j \theta_{2}}
$$

where $\theta_{2}=\theta_{1}-\theta_{r}$ and $\theta_{r}$ is rotor angle. To generate the pulse width modulation (PWM) switching patterns a Space vector modulation (SVM) is used.

To maintain the operation of the SVM in the linear zone of operation, the space rotor voltage $\bar{V}_{r m n}^{*}(k)$ is limited by the voltage limiter block (VLB) can be expressed by following functions:

$$
\begin{gathered}
\left|\bar{V}_{r m n}^{*}(k)\right|=\sqrt{v_{r m}^{* 2}(k)+v_{r n}^{* 2}(k)} \\
\theta(k)=\arctan \frac{v_{r n}^{*}(k)}{v_{r m}^{*}(k)} \\
\text { if }\left|\bar{V}_{r m n}^{*}(k)\right|>=V_{r m a x} \text { then }\left|\bar{V}_{r m n}^{*}(k)\right|=V_{r m a x} \\
v_{r m}^{*}(k)=\left|\bar{V}_{r m n}^{*}(k)\right| \cos [\theta(k)] \\
v_{r n}^{*}(k)=\left|\bar{V}_{r m n}^{*}(k)\right| \sin [\theta(k)]
\end{gathered}
$$

where $V_{r \max }$ is the maximum voltage the converter can produce.

\section{SIMULATION AND EXPERIMENTAL RESULTS}

The control scheme was initially simulated with software Matlab/Simulink. The bench for tests comprises a $2.25 \mathrm{~kW}$ DFIG mechanically coupled to the induction motor. The parameters of the DFIG used are shown in Appendix. The power control was implemented with a power electronic converter using insulated-gate bipolar transistor (IGBT) and controlled by a DSP TMS320F2812 board. The rotor speed was measured by an encoder of 1500 pulses per revolution, as can be seen on experimental setup shown in Figure 9. In the DSP programming, two interruptions were used, as described in the following:

1) In the interruption of $50 \mu \mathrm{s}$ are done

- Measurement of line stator voltage and current and conversion of $a b c$ to $\alpha \beta$ theses variables; 


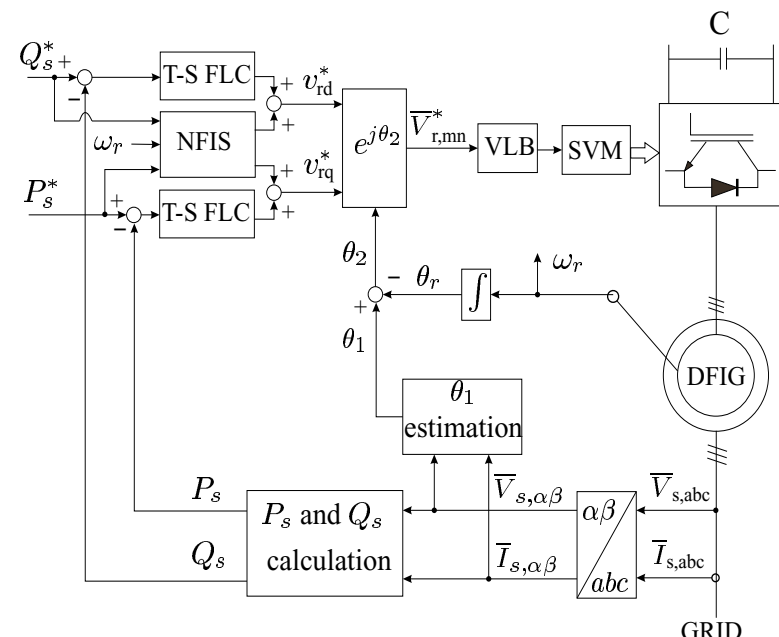

Fig. 8. Implemented control system.

- Estimation of the angular position of stator flux;

- Calculation of active and reactive power.

2) In the interruption of $200 \mu \mathrm{s}$ are done

- Calculation of rotor speed and position from the reading of the pulses generated by encoder;

- Execution of the algorithms T-S FLC and NFIS that generate the values of $v_{r d}^{*}$ and $v_{r q}^{*}$;

- Transformation of $\bar{V}_{r, d q}$ to $\bar{V}_{r, m n}$;

- Execution of the SVM algorithm.

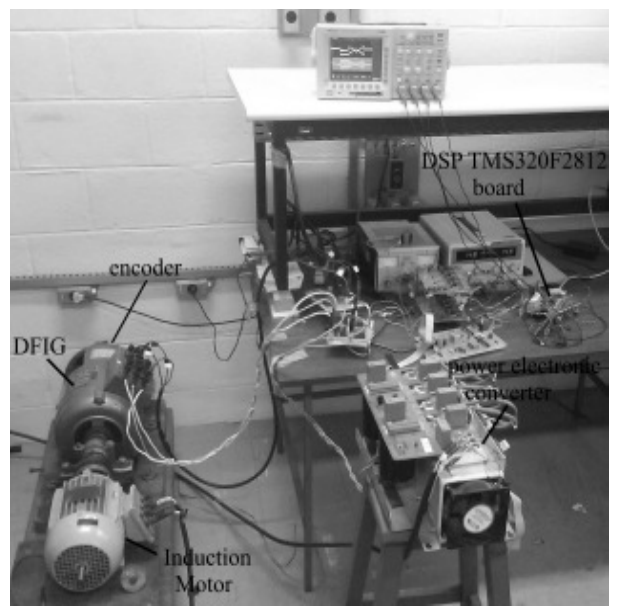

Fig. 9. Experimental setup.

The values of the gains of TS-FLC in the simulation and experiment are $G_{q s}=0.7, G_{p s}=0.9, G_{v r d}=1.5$ and $G_{v r q}=1.8$.

The simulation and experimental results are put side by side for favoring the comparative analysis. Figures 10(a) and 10(b) show the active and reactive power responses for step and linear variations and one concludes that the responses, both simulation and experimental, follow its references. The respective three-phase instantaneous currents of stator are shown in Figures 10(c) and 10(d). One observe that the rotor currents in Figures 10(e) and 10(f) present a small difference between the corresponding magnitudes. This fact is due the difficulty to synchronize the instant of simulation and experimental tests. Simulated and experimental results of the d- and q- stator flux and rotor speed are shown in Figure $10(\mathrm{~g})$ and $10(\mathrm{~h})$, where $\psi_{s d} \cong 0.48 \mathrm{~Wb}$, given by $V_{s} / \omega_{1}$, and $\psi_{s q}$ is zero, as are expected. The rotor speed decreases approximately $5 \%$ of the synchronous speed when the active power reaches $2 \mathrm{~kW}$.

Figure 11 presents the behavior of the stator phase voltage and current of the DFIG for the following experimental tests: 1) abrupt change in the active power $\left(P_{s}=0 \rightarrow-2 \mathrm{~kW}\right)$ while the $Q_{s}=0$ (Figure 11(a)), and 2) abrupt change in the reactive power $\left(Q_{s}=1 \mathrm{kVAr} \rightarrow-1 \mathrm{kVAr}\right.$ ) while the $P_{s}=-1 \mathrm{~kW}$ (Figure 11(b)). As can be seen, the proposed Neuro-fuzzy controller allows to obtain a fast response for the required active/reactive power $(\approx 2 \mathrm{~ms})$ and the phase between the current and the stator voltage is compatible with the nature of power factor, i.e., current in phase with the voltage for resistive load, lagging current for inductive load and leading current for capacitive load.

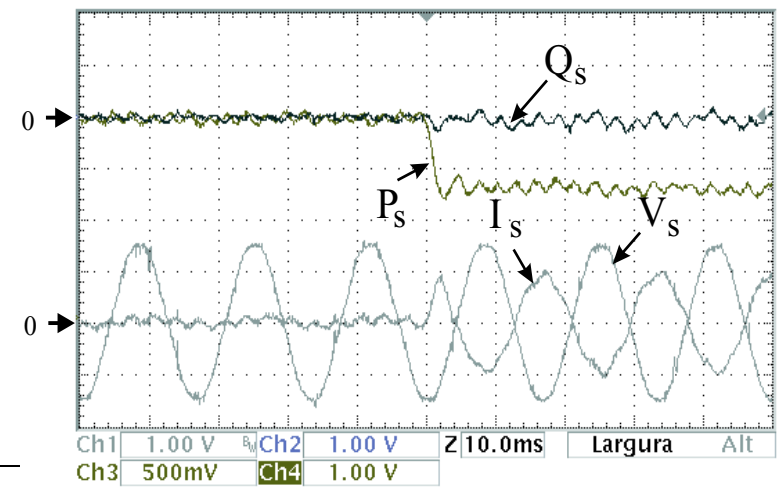

(a) $Q_{s}=0 \mathrm{VAr}$ and step for active power from 0 to $-2 \mathrm{~kW}$.

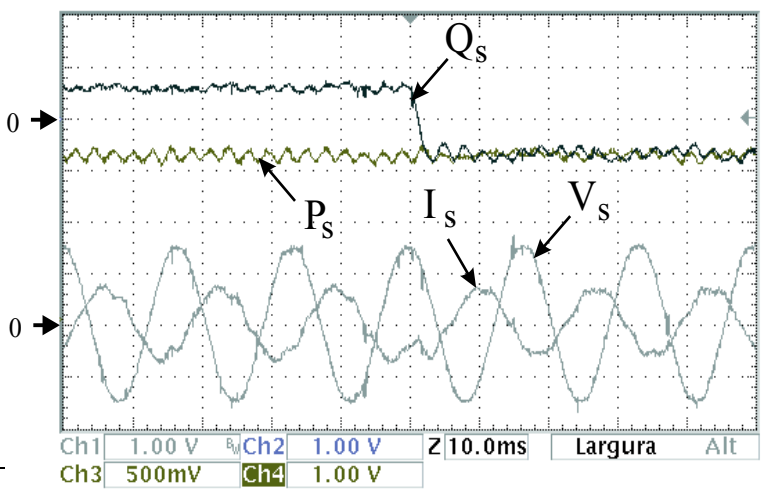

(b) $P_{s}=-1 \mathrm{~kW}$ and step for reactive power from 1 to $-1 \mathrm{kVAr}$.

Fig. 11. Experimental result under stator active and reactive power steps: stator phase current (4A/div); stator phase voltage (120V/div); active power $(1.5 \mathrm{~kW} / \mathrm{div})$; and reactive power $(1.5 \mathrm{kVAr} / \mathrm{div})$

\section{CONCLUSION}

A controller for direct power control of stator flux oriented DFIG is proposed to control stator active and reactive power 

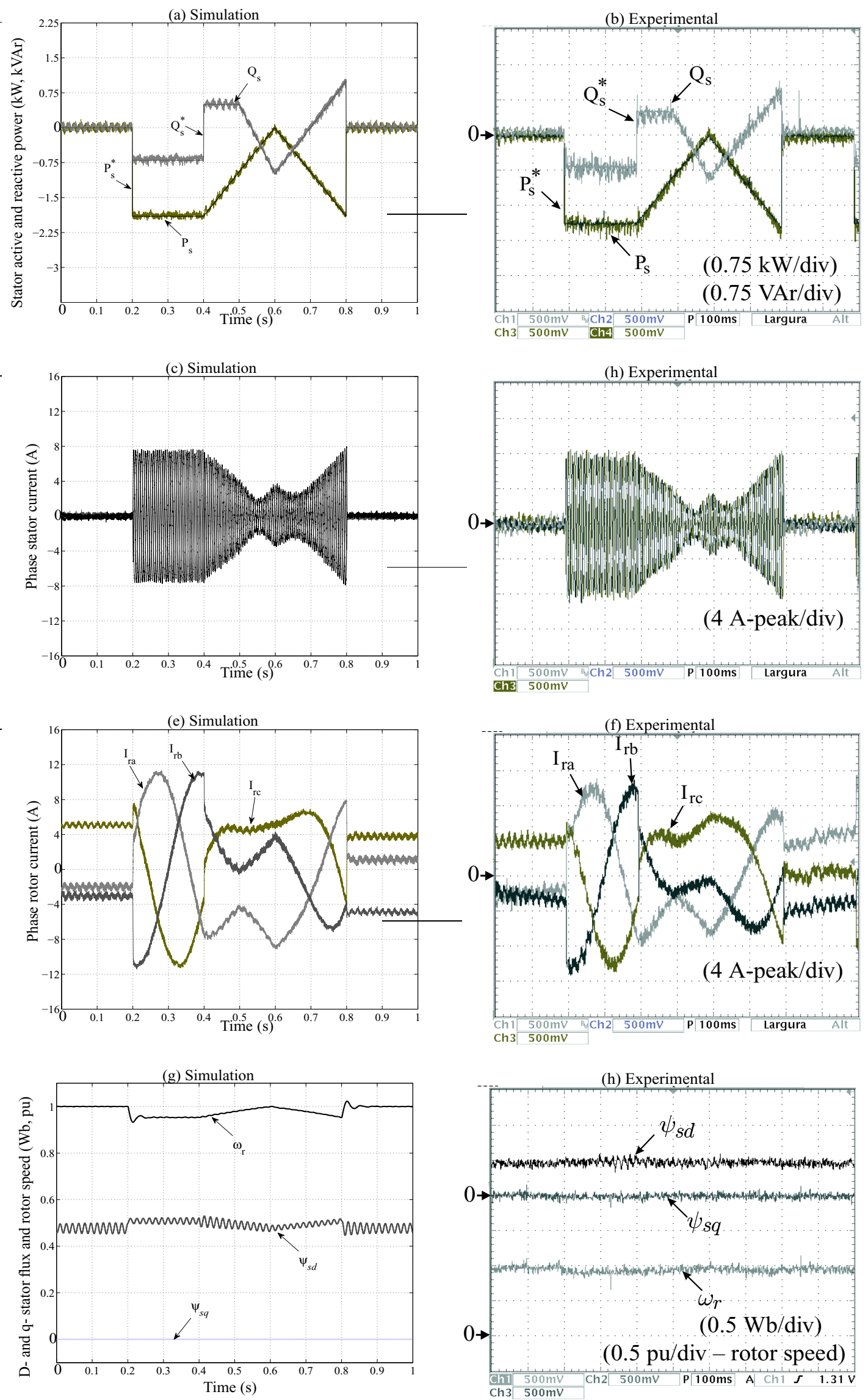

(h) Experimental

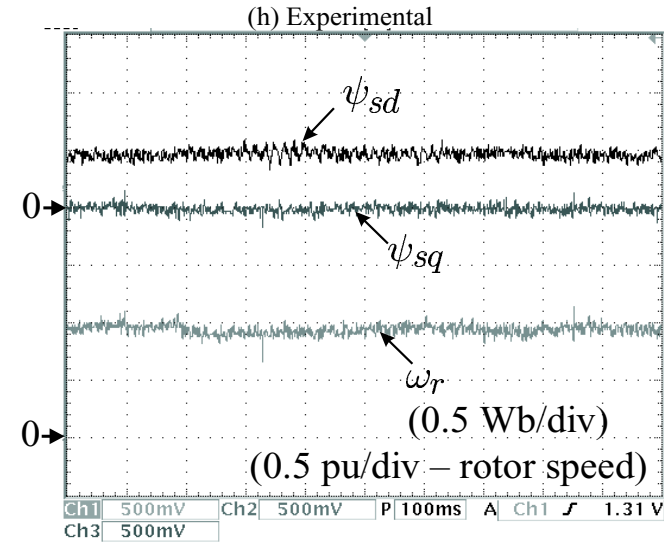

Fig. 10. Simulation and experimental results under active and reactive step and linear variations. 
directly without the need of current controller. The controller based on neural-fuzzy inference system combined to a TakagiSugeno fuzzy logic controller of first order determines the required rotor voltage components from the stator flux, the rotor position, rotor speed and the values of active and reactive power as well as their errors. The advantage of the neurofuzzy controller proposed are its simplicity, low computational cost and it is characterized as an adaptive control to different operating points. The proposed Takagi-Sugeno fuzzy logic controller requires the adjust of four gains instead of eight gains for PI controllers in cascade: two gains for each of the four PI.

With the parameters obtained by simulation, the neurofuzzy controller was experimentally tested in a DFIG. Zero steady state error, fast response of the active and reactive power, no overshoot, minimal oscillation around the steadystate operating points confirm the its feasibility, with the advantage of being rotor current-sensorless.

\section{APPENDIX}

DFIG nominal values: $2.25 \mathrm{~kW}, V_{s}=220 \mathrm{~V}, f_{s}=60 \mathrm{~Hz}$. Parameters: $R_{s}=1.2 \Omega, R_{r}=1.24 \Omega, L_{s}=98.14 \mathrm{mH}, L_{r}=98.14$ $\mathrm{mH}, L_{m}=91.96 \mathrm{mH}$ and $p=4$ poles.

TABLE I

Training data

\begin{tabular}{cccccc}
\hline $\mathrm{OP}$ & $P_{s}^{*}$ & $Q_{s}^{*}$ & $\omega_{r}$ & $v_{r q}^{*}$ & $v_{r d}^{*}$ \\
\hline 1 & 2500 & -2500 & 290 & 43,52 & 25,082 \\
2 & 0 & -2500 & 290 & 55,18 & 14,605 \\
3 & -2500 & -2500 & 290 & 66,59 & 4,325 \\
4 & 2500 & 0 & 290 & 32,048 & 15,225 \\
5 & 0 & 0 & 290 & 44,308 & 5,242 \\
6 & -2500 & 0 & 290 & 56,253 & $-4,598$ \\
7 & 2500 & 2500 & 290 & 21,806 & 4,230 \\
8 & 0 & 2500 & 290 & 34,578 & $-5,17$ \\
9 & -2500 & 2500 & 290 & 46,978 & $-14,498$ \\
10 & 2500 & -2500 & 377 & $-8,138$ & 15,569 \\
11 & 0 & -2500 & 377 & 1,843 & 15,087 \\
12 & -2500 & -2500 & 377 & 11,550 & 14,645 \\
13 & 2500 & 0 & 377 & -8.9417 & 5,149 \\
14 & 0 & 0 & 377 & 1.0951 & 5,206 \\
15 & -2500 & 0 & 377 & 10.85 & 5,238 \\
16 & 2500 & 2500 & 377 & -8.636 & $-5,281$ \\
17 & 0 & 2500 & 377 & 1.372 & $-4,684$ \\
18 & -2500 & 2500 & 377 & 11.102 & $-4,176$ \\
19 & 2500 & -2500 & 460 & -59.798 & 6,057 \\
20 & 0 & -2500 & 460 & -51.4935 & 15,57 \\
21 & -2500 & -2500 & 460 & -43.488 & 24,964 \\
22 & 2500 & 0 & 460 & -49.932 & $-4,925$ \\
23 & 0 & 0 & 460 & -42.1185 & 5,17 \\
24 & -2500 & 0 & 460 & -34.5526 & 15,076 \\
25 & 2500 & 2500 & 460 & $-39,078$ & $-14,794$ \\
26 & 0 & 2500 & 460 & $-31,834$ & $-4,199$ \\
27 & -2500 & 2500 & 460 & $-24,774$ & 6,145 \\
\hline & & & & &
\end{tabular}

The parameters of the consequents of each rule generated by ANFIS are given by: $v_{r q . j}=\{66.589 ; 11.546 ;-43.488 ; 56.253 ; 10.846 ;-34.553 ;$ $46.978 ; 11.099 ;-24.774 ; 55.064 ; 1.739 ;-51.575 ; 44.187$; $0.992 ;-42.196 ; 34.451 ; 1.269 ;-31.906 ; 43.521 ;-8.143$; $59.798 ; 32.048 ;-8.945 ;-49.932 ; 21.807 ;-8.638 ;-39.078\}$.

$v_{r d, j}=\{4.325 ; 14.645 ; 24.964 ;-4.599 ; 5.239 ; 15.076$; $14.499 ;-4.176 ; 6.146 ; 14.71 ; 15.092 ; 15.474 ; 5.343 ; 5.206$; $5.069 ;-5.075 ;-4.69 ;-4.305 ; 25.082 ; 15.569 ; 6.057 ; 15.225$; $5.149 ;-4.926 ; 4.231 ;-5.282 ;-14.794\}$.

Where $\mathrm{j}=1,2,3,4, \ldots, 27$.

\section{ACKNOWLEDGEMENT}

The authors would like to thank to the Council for Advanced Professional Training (Fundação Coordenação de Aperfeiçoamento de Pessoal de Nível Superior-CAPES) for financial support.

\section{REFERENCES}

[1] W. Leonhard. Control of Electric Drives. SpringerVerlag, 1985.

[2] F. Blaabjerg and F. Iov. Wind power - a power soucer now enabled by power electronics. In Brasilian Power Electronics Conference, 2007.

[3] R. Datta and V. T. Rangathan. Variable-speed wind power generation using doubly fed wound rotor induction machine - a comparison with alternative schemes. IEEE Trans. Energy Conversion, 17(3):414-421, Sep 2002.

[4] Peter Vas. Sensorless Vector and Direct Torque Control. Oxford Science Publications, 1998.

[5] R. G. de Oliveira, J. L. da Silva, and S. R. Silva. Desenvolvimento de uma nova estratgia de controle de potncia reativa em gerador de induo de dupla alimentao para turbinas elicas. Eletrônica de Potência, 13(4):207284, Nov. 2008.

[6] I. Takahashi and T. Noguchi. A new quick-response and high-efficiency control strategy of an induction motor. IEEE Trans. Industry Applications, (5):820-827, Sept. 1986.

[7] R. Datta and V.T. Ranganathan. Direct power control of grid-connected wound rotor induction machine without rotor position sensors. IEEE Trans. Power Electron., 16(3):1058-1066, May. 2001.

[8] R. V. Jacomini, A. França, and E. Bim. Simulation and experimental studies on double-fed induction generator power control operating at subsynchronous operation speed. In Conference on Power Electronics and Drive Systems, 2009.

[9] A. Petersson, L. Harnefors, and T. Thiringer. Evaluation of current control methods for wind turbines using doubly-fed induction machines. IEEE Trans. Power Electron., 20(1):2270-2281, Jan. 2005.

[10] F. K. de A. Lima, E. H. Watanabe, P. Rodrguez, and - Luna. Controle de gerador de induo duplamente alimentado diante de afundamentos de tenso. Eletrônica de Potência, 3(14):189-199, Agos. 2009.

[11] L. Xu and P. Cartwright. Direct active and reactive power control of dfig for wind energy generation. IEEE Trans. Energy Conversion, 21(3):750-758, May. 2006.

[12] T. G. Habertler, F. Profumo, M. Pastorelli, and L. M. 
Tolbert. Direct torque control od induction machines using space vector modulation. IEEE Trans. Industry Applications, 28(5):1045-1053, Sept./Oct. 1992.

[13] B. H. Kenny and R. D. Lorenz. Stator and rotor flux based deadbeat direct torque control of induction machines. In Conf. Rec. IEEE-IAS Annu. Meeting, volume 1, pages 133-139, 2001.

[14] C. Lascu, I. Boldea, , and F. Blaabjerg. A modifiel direct torque control for induction motor sensorless drive. IEEE Trans. Industry Applications, 36(1):122-130, Jan./Feb. 2000.

[15] D. Zhi and L. Xu. Direct power control of dfig with constant switching frequency and improved transient performance. IEEE Trans. Energy Conversion, 22(1):110-118, Mar. 2007.

[16] Sung-Tak Jou, Sol-Bin Lee, Yong-Bae Park, and KyoBeum Lee. Direct power control of a dfig in wind turbines to improve dynamic responses. Journal of Power Electronics, 9(4):781-790, Sept. 2009.

[17] Peter Vas. Application of Fuzzy, Neural, Fuzzy-Neural, and Genetic-Algorithm-Based Techniques. Oxford Science Publications, 1992.

[18] M. Vasudevan and R. Arumagam. High- performance adaptive intelligent direct torque control schemes for induction motor drivers. KMITL Sci. Tech. J., 5(3):559576, Jul.-Dec. 2005.

[19] J.-S. R. Jang. Anfis: Adaptative-network-based fuzzy inference system. IEEE Trans. Syst., Man, Cyber., 23(3):665-684, May/June 1993.

[20] J.-S. R. Jang and C.-T. Sun. Neuro-fuzzy modeling and control. Proc. IEEE, 83(3):378-406, Mar. 1995.

[21] Z. P. Grabowski, M. P. Kazmierkowski, B. K. Bose, and F. Blaabjerg. A simple direct-torque neuro-fuzzy control of pwm-inverter-fed induction motor drive. IEEE Trans. Industrial Eletronics, 47(4):863-870, Aug. 2000.

[22] Edson Bim. Máquinas Elétricas e Acionamento. Elsevier Publications, 2009.

[23] T. Takagi and M. Sugeno. Fuzzy identification of systems and its applications to modeling and control. IEEE Transactions on Systems, Man and Cybernetics, 15(1):116-132, Febr. 1985.

\section{BIOGRAPHIES}

Rogério Vani Jacomini was born in Santa Barbara D' Oeste, Sao Paulo, Brazil, in 1979. Received the B.S. degree in electrical engineering from Salesian University Center of Sao Paulo, Brazil, in 2004, the M.S. degree from State University of Campinas, Brazil, in 2008. Currently, he is working toward the Ph.D. degree at the State University of Campinas, Brazil. His current research interest include AC drives and and doubly fed induction machine.

Edson Bim received the BS, MS and doctorate degrees in Electrical Engineering from State University of Campinas, Brazil, in 1976, 1981 and 1993, respectively. He is currently an associate professor at State University of Campinas. His research interests are AC drives and doubly fed induction generator. 